\title{
'Am I going to see the next morning?' A qualitative study of patients' perspectives of sleep in COPD
}

\author{
* Bryanie S Shackella, Rupert CM Jones ${ }^{b}$, Geoffrey Hardingc, Steve Pearsed, John Campbelle \\ ${ }^{a}$ Research Manager, Primary Care Respiratory Research Unit, Peninsula Medical School, ITTC North, Tamar Science Park, Davy Road, Plymouth, \\ PL6 8BX, UK \\ ${ }^{\mathrm{b}}$ Clinical Research Fellow, Primary Care Respiratory Research Unit, Peninsula Medical School, Plymouth \\ c Research Facilitator, Institute of Health Service Research, Peninsula Medical School, Plymouth \\ d Respiratory Specialist Nurse, Chest Clinic, Plymouth Teaching Primary Care Trust, Derriford Hospital, Plymouth \\ e Professor of Primary Care, Department of Primary Care, Peninsula Medical School, Smeall Building, St Luke's Campus, Magdalen Road, \\ Exeter.
}

Received 19th April 2007; accepted 19th October 2007

\begin{abstract}
Aim: To investigate patients' perspectives of sleep in COPD.

Method: Patients with moderate to severe COPD underwent semi-structured interviews about their sleep experiences. Contextual questionnaire data were collected.

Results: Ten patients were studied. Six reported bad sleep, but all described some sleep problems. Nocturnal anxiety and fears of breathlessness and dying were common features; these impacted on existing sleep problems related to exacerbations, medications, and habitual behaviours that can disrupt sleep. Poor sleep was associated with poorer health status. Patients reported a lack of support from their GPs and few had received advice for sleep problems.

Conclusion: Anxiety about breathlessness affects the sleep experience of patients with COPD, and sleep quality impacts on physical and emotional functioning. Education about behaviours that can disrupt sleep offers potential benefits to the patient. COPD patients' sleep issues are complex and should be addressed at the clinical consultation.

(C) 2007 General Practice Airways Group. All rights reserved.

BS Shackell, et al. Prim Care Resp J 2007; 16(6): 378-383.

doi:10.3132/pcrj.2007.00078
\end{abstract}

Keyw ords Sleep, COPD, primary health care, qualitative research, patients' perspective, anxiety, breathlessness

\section{Introduction}

Sleep problems affect more than $50 \%$ of patients with chronic obstructive pulmonary disease (COPD) ${ }^{1}$ and the physiological effects of sleep-related changes in breathing have been extensively researched. ${ }^{2}$ In COPD, breathing against expiratory airflow obstruction becomes more difficult during sleep when there is reduced tidal volume, inefficient ventilation and hypoxaemia. ${ }^{3}$ Hypoxia predisposes to pulmonary hypertension, cardiac arrhythmias, ${ }^{3}$ cor pulmonale and nocturnal death. ${ }^{2,4}$ Difficulties falling asleep, frequent awakenings, ${ }^{2,3}$ superficial sleep, ${ }^{5}$ daytime sleepiness, ${ }^{6}$ and morning tiredness ${ }^{7}$ have been reported.

Poor or inadequate sleep impacts on physical and emotional functioning, increasing anxiety and daytime fatigue (a prominent symptom of COPD), and impaired coping ability, cognitive function, and exercise tolerance; this in turn leads to de-motivation, reduced activity, decline in physical condition, and impaired quality of life. ${ }^{2,3}$

Although non-drug interventions such as cognitive behavioural therapy can be useful in the treatment of sleep problems in COPD,${ }^{8}$ much depends on the patient's perspective as to whether a sleep disturbance constitutes a 'problem'. Since COPD is a progressively debilitating condition requiring considerable modifications in lifestyle and activity levels, ${ }^{9}$ it is conceivable that patients' attitudes to sleep might also be affected in this process.

\footnotetext{
*Corresponding author: Tel: +44 (0)1752 764451 Fax: +44 (0)1752 764259 E-mail: bshackell@pms.ac.uk
} 
In this study, we aimed to investigate sleep in COPD patients - from the patient's perspective - by exploring sleep experiences, sleep quality, sleep management strategies, and the role of sleep in quality of life.

\section{Methods}

Participants were recruited by a community Respiratory Specialist Nurse (RSN) who asked patients if they were willing to discuss their sleep with a researcher. Having a 'sleep problem' was not a criterion for study entry. Patients were then contacted by the researcher who checked compliance with the study criteria and willingness to participate.

Inclusion criteria were moderate to severe airflow obstruction ( $F E V_{1}<80 \%$ predicted) together with significant disability from breathlessness according to the MRC dyspnoea scale. ${ }^{9}$ Exclusion criteria were: oxygen de-saturation at rest less than $<90 \%$; recent discharge from hospital; clinical history of loud snoring with apnoea; obstructive sleep apnoea; sleep disorders; significant co-morbid illness with sleep disturbance; confusion; and learning disability or other conditions which would impair the patient's ability to participate.

Study procedures were undertaken at the patients' homes. Written informed consent was obtained prior to collection of demographic data

\section{Questionnaire data}

Validated questionnaires were completed to obtain contextual measures of patients' sleep, mood, and disease characteristics. The questionnaires used were as follows;

(1) The Chronic Respiratory Disease Questionnaire (CRDQ) ${ }^{10}$ used to assess the effect of the patient's disease on quality of life in four domains: dyspnoea; mastery; fatigue; and emotional function.

(2) The Hospital Anxiety and Depression Scale (HAD) ${ }^{11}-a$ validated self-assessment scale for anxiety and depression.

(3) The Pittsburgh Sleep Quality Index (PSQI) ${ }^{12}$ - a validated, standardised questionnaire measuring sleep quality and sleep disturbances during the previous month. It has seven components: subjective sleep quality; latency; duration; habitual sleep efficiency; sleep disturbances; use of sleep medication; and daytime dysfunction.

(4) The Epworth Sleepiness Scale (ESS) ${ }^{13}$ - measures the general level of daytime sleepiness.

\section{Audio-recorded semi-structured interviews}

Subjects were interviewed alone for approximately one hour. Interviews followed the topic guide (Box 1) according to the principles outlined by Kvale. ${ }^{14}$ Interview content was developed in part from the literature on sleep and COPD, and was modified in the light of responses to the initial interviews.

Recordings were transcribed verbatim and analysed along the principles outlined by Harding and Gantley. ${ }^{15}$ Transcripts were analysed iteratively, key concepts were mapped, and

\section{Box 1. Interview topic guide}

(1) Health and COPD: How do your breathing problems affect you these days?

Symptoms: Aspects of breathing problems/disease which are most bothersome

COPD: Effects of breathing problems on everyday life Treatment: What gives most relief from breathing problems?

(2) Sleep experiences: Problems with sleep Expectations: Expectations of sleep and sleep pattern Poor sleep: Definition of a poor/bad night's sleep Causes: Causes of a bad night's sleep COPD Effect: How might breathing problems have affected sleep? Sleep quality: What would be the best sleep you would expect to have these days?

(3) Daytime condition: How do you generally feel in the morning and during the day?

Fatigue: Does anything make you feel particularly tired in the day? Daytime tiredness: What circumstances might make you take a nap during the day?

Coping methods: What do you usually do when you have a bad night? Coping methods: Circumstances that might allow rest or less activity in the day

Relationships: How does a poor sleep affect your home/family life? Mood: How do you feel in yourself after a bad night? Importance: Aspects of breathing problems that most affect overall feeling of well being

(4) Assistance: Have you ever sought advice on improving your sleep?

Sleeping pills: What sort of things have you taken or tried to help you sleep?

Interventions: What do you think would most help you to improve your sleep?

emergent themes were extracted, revisited and refined. Particular attention was paid to discordant voices or dissonant cases i.e. elements of the transcript that did not readily accommodate a theme but were notable for future analysis. The emergent themes, together with the interviewer's fieldnotes, formed the basis of analytical interpretation.

\section{Results}

Eleven patients were invited to participate in the study between September and November 2005, and six males and four females were recruited. Mean age was 65.8y (51.0-78.0y).

Six subjects had moderate airflow obstruction [mean $\mathrm{FEV}_{1} \%$ predicted of $36.5 \%$ (31.3-43.5)], four had severe airflow obstruction [(mean $\mathrm{FEV}_{1} \%$ predicted of $24.8 \%$ (18.6-27.5)]. One subject required domiciliary oxygen therapy. 
Table 1. Pittsburgh Sleep Quality Index (PSQ I)* for subjects ( $n=10)$.

\begin{tabular}{|c|c|c|c|c|c|c|c|c|}
\hline $\begin{array}{l}\text { Subjective } \\
\text { sleep } \\
\text { quality }\end{array}$ & $\begin{array}{c}\text { Subjective } \\
\text { sleep } \\
\text { quality }\end{array}$ & $\begin{array}{c}\text { Sleep } \\
\text { latency }\end{array}$ & $\begin{array}{c}\text { Sleep } \\
\text { duration }\end{array}$ & $\begin{array}{l}\text { Habitual } \\
\text { sleep } \\
\text { efficiency }\end{array}$ & $\begin{array}{c}\text { Sleep } \\
\text { disturbances }\end{array}$ & $\begin{array}{c}\text { Sleep } \\
\text { medication }\end{array}$ & $\begin{array}{c}\text { Daytime } \\
\text { dysfunction }\end{array}$ & $\begin{array}{c}\text { GLOBAL } \\
\text { PSQI } \\
\text { SCORE }\end{array}$ \\
\hline \multirow[t]{4}{*}{ Good $(n=4)$} & 0 & 1 & 1 & 1 & 1 & 0 & 0 & 4 \\
\hline & 0 & 0 & 0 & 0 & 1 & 0 & 1 & 2 \\
\hline & 1 & 3 & 1 & 1 & 2 & 0 & 0 & 8 \\
\hline & 0 & 1 & 1 & 0 & 2 & 0 & 1 & 5 \\
\hline \multirow[t]{6}{*}{ Poor $(n=6)$} & 3 & 3 & 3 & 3 & 3 & 0 & 2 & 17 \\
\hline & 3 & 3 & 3 & 1 & 2 & 3 & 2 & 17 \\
\hline & 2 & 1 & 3 & 3 & 2 & 0 & 0 & 11 \\
\hline & 2 & 3 & 2 & 3 & 2 & 0 & 2 & 14 \\
\hline & 3 & 3 & 3 & 3 & 2 & 0 & 2 & 16 \\
\hline & 3 & 3 & 3 & 3 & 2 & 0 & 2 & 16 \\
\hline Mean & 1.7 & 2.1 & 2.0 & 1.8 & 1.9 & 0.3 & 1.2 & 11.0 \\
\hline sd & 1.3 & 1.2 & 1.1 & 1.3 & 0.6 & 0.9 & 0.9 & 5.8 \\
\hline sd & 1.3 & 1.2 & 1.1 & 1.3 & 0.6 & 0.9 & 0.9 & 5.8 \\
\hline
\end{tabular}

Co-morbid illnesses included arthritis (three subjects), depression (two subjects), angina (two subjects), and asthma (two subjects). All subjects were taking inhaled bronchodilators. Other medication included corticosteroids (five subjects), diuretics (four subjects), antibiotics (four subjects), and antidepressants (two subjects).

Mean scores for the PSQI domains are shown in Table 1. Using the classifications given in the PSQI, subjects rated their sleep quality as being either 'very bad' (four subjects), 'fairly bad' (two subjects), 'very good' (three subjects) or 'fairly good' (one subject). Patients were subsequently grouped into 'good' sleepers and 'bad' sleepers for the purposes of descriptive analysis. Global PSQI scores for overall sleep quality also reflected these ratings.

For all subjects, mean subjective sleep latency was 42 minutes (sd: 33mins; range 5 minutes to more than 2 hours), mean sleep duration was 5 hours (2.5-8.0) and mean habitual sleep efficiency 68\% (25-100\%).

During the night, nine subjects needed to visit the bathroom at least three times, six were unable to breathe comfortably at least once, and five were disturbed by pain at least once. Seven found their sleep quality affected their enthusiasm to get things done during the day.

Table 2 presents a summary of contextual data for all subjects and for the groups of 'bad' and 'good' sleepers. Compared to 'good' sleepers, 'bad' sleepers had lower values for $\mathrm{FEV}_{1} \%$ predicted, and CRDQ domains, and higher scores for anxiety and depression (HADS).

\section{Subjective sleep experiences}

All subjects had experienced sleep problems. Typically, 'good' sleepers described sleep problems related to exacerbations, whereas the 'bad' sleepers reported recurring difficulties with sleep onset and sleep maintenance. Sleep problems included difficulty falling asleep, restlessness, being unable to 'switch off' and relax at night, frequent nocturnal awakenings, and episodes of prolonged wakefulness;

'It just feels as if you want to go to sleep but you just can't - you can't rest your mind. It just won't let you go to sleep, you keep snapping in and out of doziness, like, you know.' [M: 71y].

'So I lie there, toss and turn, turn and toss. After (what) I think is a reasonable length of time, maybe half an hour sometimes an hour, I put the light on again and I look and I think so I get out of bed and I come down and I make myself another drink, then go back up, get my book out again, try and read for a little while and then, now this can happen three and four times in one night or it can happen just once and it's most awful you know'. [F: 78y]

\section{Beliefs about sleep quality}

Subjects were frustrated by the effects of their COPD, but felt that they had 'learned to live with it'. Although they expected to sleep less because of their age, illness, reduced activity and limited lifestyle, insomnia caused considerable frustration and 
Table 2. Percentage FEV1 (predicted), CRDQ, HAD and ESS for good and poor sleepers and all subjects.

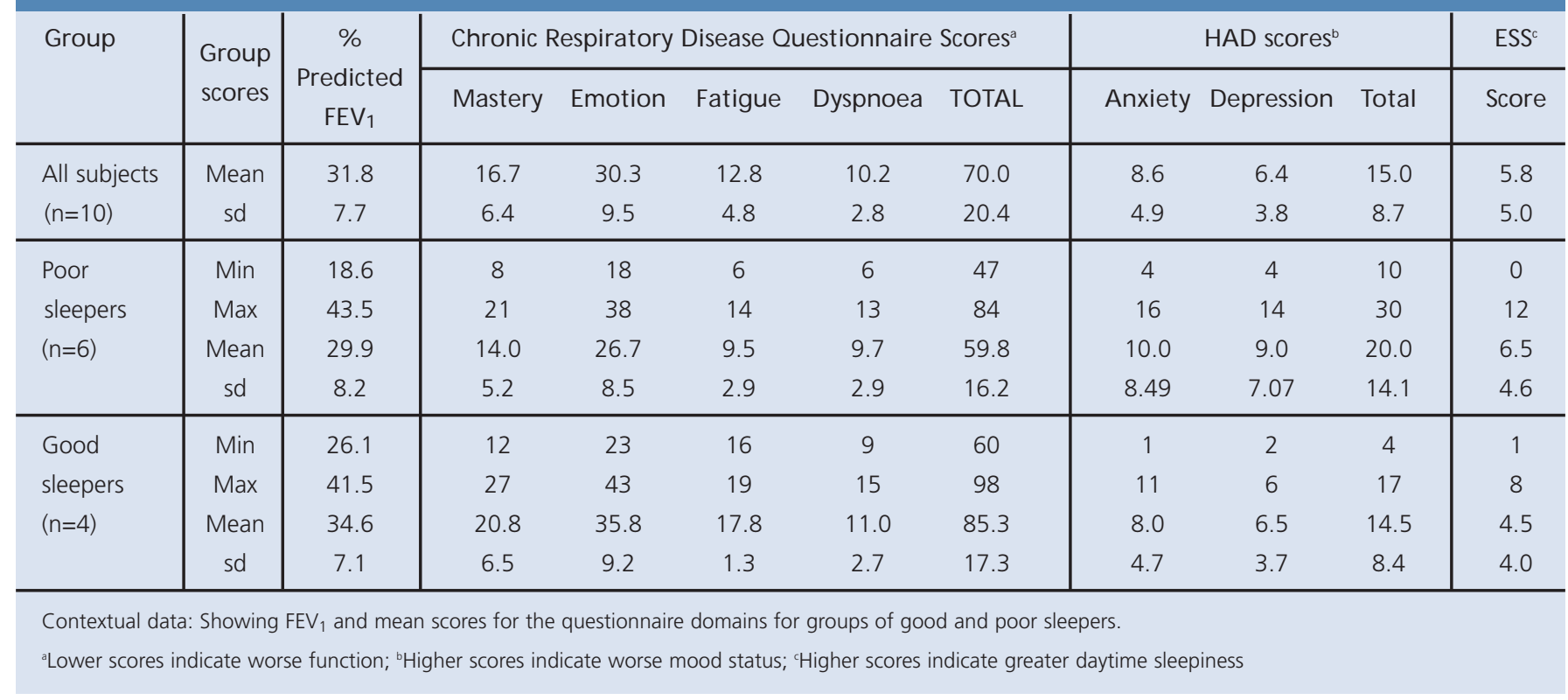

anxiety about the next day, and subjects recognised that sleep quality impacted on their physical and emotional well being;

'I know inside my own head if you mentally feel unwell you bodily feel unwell. If you're mentally feeling good, if you've had a good night's sleep and your mind's waking up fresh, it gives your body a lift.' [M: 51y].

'If you're tired you know, er, if you can't get enough sleep and you're exhausted and dead beat in the morning; sometimes you ain't got time for nothing. You know, you just - even if you could - you - you just - you've just had it, you've just had it.' [M: 64y]

Two themes, 'Nocturnal fear and anxiety' and 'Barriers to effective sleep strategies' emerged from the qualitative interviews;

\section{Noctumal fear and anxiety}

Anxiety and fear of breathlessness dominated the subjects' daily experiences, limiting physical and social activities and impairing their quality of life. All subjects described sudden episodes of breathlessness which invoked panic, further anxiety and breathlessness. At night subjects felt vulnerable and isolated from daytime support mechanisms. Many expressed fears of breathlessness, panic, and dying during their sleep;

'But sometimes during the night it gets frightening. I will say that... well, er, you feel something coming on, er, you sense your breathing's not too good or it's getting worse and panic sets in a bit and makes it that little bit more worse.' [M: 64y]
'I think a lot of it as well is 'am I gonna see the next morning?' Well with my complaint, you know, you get an illness and you don't know whether you're gonna see the next morning. Like my dad died twelve months ago, and he had lung trouble, and he fell asleep in his chair.' [F: 52y]

'Yeah, just the breathlessness frightens me. When I'm on my own, if I'm on my own I'm afraid that something might happen to me, you know, and I'm on my own, there's nobody here, that's what I'm afraid about.' [F: 66y]

Some had slept better in hospital where they felt safe and secure;

'But erm, a couple of times I did wake up breathless in the hospital. But luckily they had a - an oxygen mask beside me. So I was able to take a couple of puffs of that and went back to sleep again'. [M: 76y].

'I used to get a good sleep, like I said, when I went into hospital'. [F: 65y].

and some felt safer sleeping during the day;

'I just don't like to sleep at night.' [F: 52y]

\section{Bamiers to effective sleep strategies}

Subjects had established behaviours known to disrupt sleep, for example eating and drinking caffeinated drinks late at night, watching late night television, taking naps in the day or evening. 
'Sometimes I can't go to sleep. Then I'll go to the kitchen, make a sandwich and a cup of tea, drink it in the night, yeah. That's my routine.' [M:64y]

'I just wait as long as I can with the television on, whether it's interesting or not.' [M:64y]

Many found that napping provided a refreshing relief from both fatigue and boredom;

'That's the trouble - I'm bored out of my mind.' [F: 78y]

'If I'm very tired, I can probably sleep for the hour, but if I'm not very tired, half an hour would do me. Sometimes ten minutes, and I'm refreshed.' [M: 76y]

Subjects had been advised to drink water to relieve coughing and dry mouth caused by medications, which resulted in frequent nocturnal diuresis;

'Well, I was drinking a lot of water because I was coughing a lot, so I drunk a lot of water to stop the cough because that's what the doctor said, you know, drink water and plenty of it every time you cough, you know, and it used to work. And then I used to go toilet more often then, during the night.' [F: 66y]

...that leaves me with a complete dry mouth and dry throat because I think the [inhaler] I take it's just that little bit of a clash. So I find I'm forever getting up for a drink and getting up - I mean I'm forever up and down to the toilet, you know.' [M: 51y]

'If I've taken the steroids for any length of time then, normally I was taking them eight for five days when I'm ill, and if I've got to carry on with them after that, I do wake up in the night and can't get back to sleep.' [F: 72y]

Two subjects had sought advice for their sleep problems, but were unhappy with their treatment;

I've lost all my confidence in Dr... because when l've been down and spoken to him about ......the breathlessness or I can't sleep, he just don't seem to be a bit concerned .' [F: 65y]

'Well the doctors won't give me any sleeping pills... because they say if I - they're afraid I'd go into too deep a sleep and I won't wake up. ' [F: 52y]

\section{Discussion}

Whereas previous studies have looked at the physiological
Figure 1. Dynamics of disrupted sleep in ten subjects with moderate to severe COPD

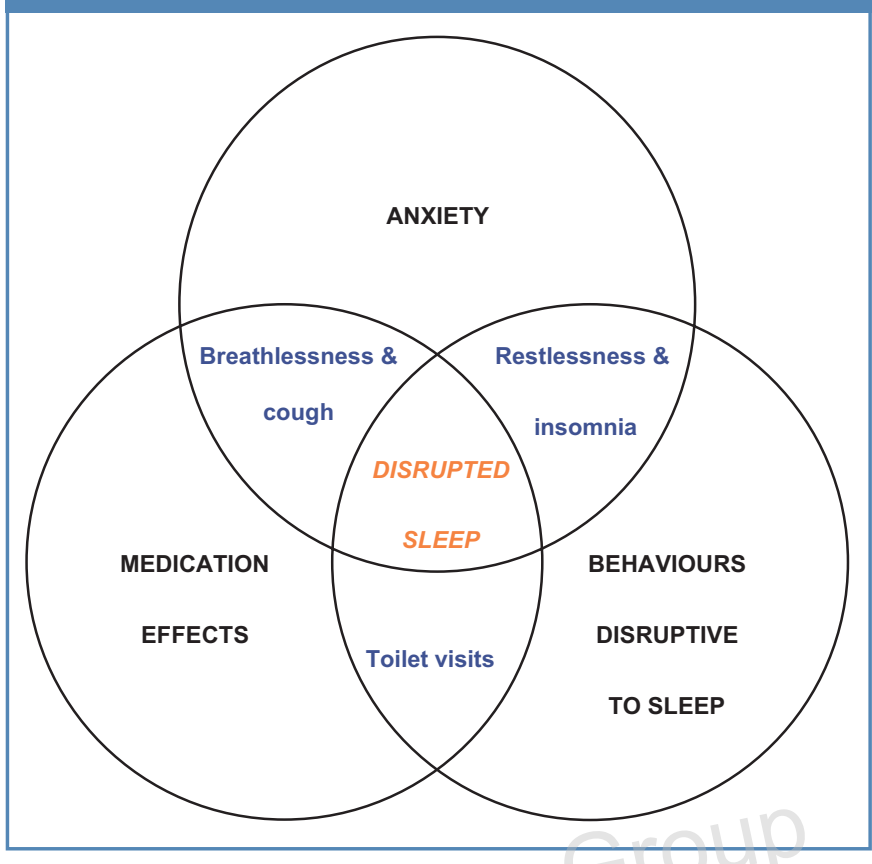

effects of sleep in COPD patients, the aim of this study was to explore sleep from the patients' perspective. The qualitative approach revealed that patients' anxiety and fears of breathlessness, panic, and dying, extended into the night and were aggravated by feelings of isolation, vulnerability and frustration. Comfort-seeking behaviours such as tea drinking, TV watching and daytime napping perpetuated the sleep disruption. Subjects recognised a relationship between their sleep quality, mood, and well-being, which was supported by contextual data. Furthermore, participants reported sleeping better when support mechanisms were easier to access, e.g. in hospital or respite care, and during the daytime.

Patients with moderate to severe COPD experience a gradual loss of control over their daily living activities which can result in impaired physical and emotional states, and reduced quality of life. ${ }^{9}$ Whereas concern about breathlessness is a key feature of $\mathrm{COPD},{ }^{9}$ it is recognised that the sleep problems reported in this study could have resulted from a number of factors known to impair sleep quality - for example, age, ${ }^{16}$ anxiety, ${ }_{1}^{17}$ depression, ${ }^{18}$ and maladaptive behaviours towards sleep. ${ }^{8}$ In COPD, anxiety is related to chest symptoms, dyspnoea and decreased functional status, ${ }^{17}$ whereas depression is associated with difficulty falling asleep, early morning awakening, and daytime fatigue. ${ }^{18}$

Figure 1 illustrates how sleep in COPD may be disrupted by an interaction of nocturnal anxiety, symptoms, medications and maladaptive behaviours.

Although subjects reported feeling tired in the day, daytime sleepiness did not seem to pose a problem. All were able to take naps, which relieved boredom and fatigue and made nocturnal 
sleep loss more manageable. This capacity to recover some sleep could explain why only two subjects had sought help for their sleep problems, although apathy, poor expectations and medical nihilism could also have contributed.

In this study, the collection of contextual data proved helpful in supporting patients' accounts of their sleep experiences, although the small numbers prohibit anything more than a descriptive analysis. It is also recognised that the small sample size and single recruitment source - via the RSN - limit the degree to which the results of the study can be generalised. The number of patients who were recruited was also limited by the exclusion of significant co-morbidities, and the limited time and funding.

This study raises questions concerning the prevalence of nocturnal anxiety about breathlessness in patients with COPD and how this can be addressed by clinicians who care for these patients. It has also demonstrated the need to address sleep issues during clinical consultations with patients who have COPD. Where this has been incorporated into clinical practice, patients have reported that discussing sleep matters has been very helpful.

The strength of this exploratory study lies in its unique qualitative approach to sleep in patients who have COPD. The investigation into the patients' perspectives has revealed how patients' anxieties and fears of breathlessness can impair sleep quality and feelings of well being, yet many patients perceive a lack of interest in sleep problems from their physicians.

There are many complex issues relating to sleep problems in patients with COPD, highlighting the need for a holistic approach. Further research is needed to determine the prevalence of sleep problems and to develop effective holistic interventions - which might include simple measures such as good sleep hygiene education, or cognitive behavioural therapy.

\section{Conclusion}

Anxiety about breathlessness is a key feature in the sleep experiences of patients who have COPD, although large scale research on the prevalence and impact of sleep problems is needed to investigate this further.

Anxiety, inactivity, poor expectations, lack of information, and maladaptive behaviours towards sleep, contribute to sleep problems in patients who have COPD and may be amenable to non-drug interventions including anxiety management and patient education.

Patients' sleep quality should be addressed in clinical consultations since improvements in sleep quality could offer them important benefits.

\section{Funding}

This research was funded by the Peninsula Medical School.

\section{Ethics approval}

Approval was obtained from South Devon Research Ethics Committee.

\section{Competing interests}

None declared.

\section{References}

1. Klink M, Quan SF. Prevalence of reported sleep disturbances in a general adult population and their relationship to obstructive airways diseases. Chest 1987; 4:540-6.

2. McNicholas WT. Impact of Sleep in COPD. Chest 2000;117:48S-53S

3. Douglas NJ. Sleep in patients with chronic obstructive pulmonary disease. Clin Chest Med 1998;19(1):115-25.

4. WeitzenbluM E, Chaouat A, Charpentier C, et al. Sleep-related hypoxemia in chronic obstructive pulmonary disease: causes, consequences and treatment. Respiration 1997;64(3):187-93

5. Sandek K, Andersson T, Bratel T, Hellstrom G, Lagerstrand L. Sleep quality, carbon dioxide responsiveness and hypoxemic patterns in nocturnal hypoxemia due to chronic obstructive pulmonary disease (COPD) without daytime hypoxemia. Respir Med 1999;93(2):79-87.

6. Cormick W, Olson LG, Hensley MJ, Saunders NA. Nocturnal hypoxemia and quality of sleep in patients with chronic obstructive lung disease. Thorax 1986; 41(11):846-54.

7. Bellia V, Catalano F, Scichilone N, et al. Sleep disorders in the elderly with and without chronic airflow obstruction: the SARA study. Sleep 2003;26(3):318-23.

8. George CF, Bayliff CD. Management of insomnia in patients with chronic obstructive pulmonary disease. Drugs 2003;63(4):379-87.

9. The National Collaborating Centre for Chronic Conditions. Chronic Obstructive Pulmonary Disease: National Clinical Guideline on management of chronic obstructive pulmonary disease in adults in primary and secondary care. Thorax 2004;59(Suppl I):1-232.

10. University Hospitals of Leicester NHS Trust, Glenfield Hospital and McMaster University 2001. Chronic Respiratory Disease Questionnaire (self reported)

11. Zigmond AS, Snaith RP. The Hospital Anxiety and Depression Scale. Acta Psychiatra Scandinavica 1983;67:361-70.

12. Buysse DJ, Reynolds CF 3rd, Monk TH, Berman SR, Kupfer DJ. The Pittsburgh Sleep Quality Index: A New Instrument for Psychiatric Practice and Research. Psychiatry Res 1989;28(2):193-213

13. Johns MW. A new method for measuring daytime sleepiness. The Epworth Sleepiness Scale. Sleep 1991;14(6):540-545

14. Kvale S. Interviews: An introduction to qualitative research interviewing Thousand Oaks, CA: Sage Publications, 1996

15. Harding G, Gantley M. Qualitative Methods: Beyond the Cookbook. Family Practice 1997:15:76-9.

16. Foley DJ, Monjan AA, Brown SL, Simonsick EM, Wallace RB, Blazer DG. Sleep complaints among elderly persons: an epidemiological study of three communities. Sleep 1995;18(6):425-32.

17. Brenes GA. Anxiety and chronic obstructive pulmonary disease: prevalence, impact, and treatment. Psychosom Med 2003;65(6):963-70.

18. Van Manen JG, Bindels PJE, Dekker FW, ljzermans CJ, Van der Zee JS, Schade E. Risk of depression in patients with chronic obstructive disease and its determinants. Thorax 2002:57:412-16.

Available online at http://w ww.thepcrj.org 